\title{
The Extent of the Zambian Government's Support in Eradicating the Challenges Faced by Early Childhood Teachers in Zambia
}

\author{
Article by Precious Lubinda \\ David Livingstone College of Livingstone, Zambia \\ E-mail: preciousnawa4@gmail.com
}

\begin{abstract}
Early childhood is a crucial period for the development of children's mental functions; hence it needs to be handled by qualified teachers who are well motivated. The purpose of the study is to highlight some of the challenges faced by ECE teachers in rural areas and how much efforts have been made by government in terms of policies, funding, curriculum and infrastructure. A case study of early childhood provision in rural areas of Mongu district of Western Province, was presented as an example of challenges in a remote rural of Zambia. Using questionnaires and observations from the visited schools, ECE teachers are faced with a number of challenges. Based on this background, ECE teachers are supposed to be qualified in order to be able to comprehend the developmental process of ECE children. The study results revealed that most administrators, teachers, had very little knowledge on ECE provisions, and teachers were rarely monitored by standard officers to take stock of the ECE delivery system in rural areas. Also, among other findings, ECE teachers were overloaded with other responsibilities giving them less time to prepare adequately for their classes. The study was set to investigate challenges faced by preschool teachers in rural areas, and suggest measures that could be addressed by the government and other stakeholders to ensure that there is quality delivery of early childhood education regardless of the geographical positions of the centers. Other researchers who may be interested to verify on these challenges are free to do so.
\end{abstract}

Keywords: Early childhood education, curriculum, infrastructure, conducive environment, Policy

\section{Introduction}

Early childhood education is very vital in the development of children as it lays a foundation for future education. Early childhood education plays a role in shaping positive behaviour in children because it helps to form social cohesion and peace building. When children participate in early childhood education activity, their participation is positively associated with gains in school achievements, intelligence tests, reduced grade repetition and reduced misplacement of provisions for special education. This therefore, entails that preschool teachers need motivation in terms of conducive environment, adoption of appropriate learning and teaching materials, in order for them to deliver effectively. Equal opportunities must be provided to ECE teachers in order for them to contribute positively to the well-being of children.

In the recent past, there has been a growth in interests in early childhood education among different stakeholders, because children that are exposed to early childhood education perform fairly well and better than those who had no opportunity for the preschool leaning. Research shows that child development does not only affect the child's well-being, but also his or her capacity to contribute to the well-being of society in general. For instance, the importance of early childhood education for all children was endorsed in the World declaration on Education for All (Joimtien, Thailand, 1990) and the Convention on the rights of the Child (1998). A number of studies link ECE to increases in school readiness for primary school, and it has shown that school readiness is an important predictor of early school achievement (Forget-Dubois et al 2007).The government of Republic of Zambia has also recognized the important role of early childhood education in child development as reflected in the Sixth National Development Plan (2011-2015). The policy on education - Educating Our Future of 1996 also brings out the importance of early childhood education in building early experiences in the child. 
In addition, the policy brings out the need for early childhood education in building up "cultural capital" and to compensate for disadvantages that may arise from disadvantaged homes where reading, writing, or other education-related materials are absent (Ministry of Education (MoE 1996). There is a growing consensus among scholars such as Brimbring (2001, 2006 and 2007); and Osborne and Adic (2005) that experiences of children in their early years are very important in affecting their long term cognitive, social, emotional, physical and intellectual development. It has been shown that Early Childhood Education (ECE) can be a major input into a child's formal education. To this effect, experiences should include formal and informal education. Regarding the development of ECCE, it further noted major challenges in this sub-sector in past years: fragmented curriculum; lack of standards, monitoring and supervision; and the confinement of ECCE to pre-schooling instead of offering a more comprehensive learning experience (Kamerman, 2006).

\section{General objective of study}

The main aim of the study was to enlighten both public and private schools' owners on the importance of reducing challenges in early childhood education in order to allow effective delivery of education and develop interest in the young children.

\section{Specific objectives}

The study set out:

- To investigate the challenges affecting Early Childhood Education teachers in rural areas of the Western Province of Zambia.

- To determine the extent of government's support in eradicating the challenges faced by early childhood teachers in rural schools in Zambia.

- To examine the effect of lack of proper infrastructure in the provision of early childhood education in rural Zambian schools.

\section{Statement of problem}

The extent of the Zambian government's support in eradicating the challenges faced by early childhood teachers in Zambia such as infrastructure, teaching materials, over enrollment and long distances to schools.

\section{Rationale of the study}

The study was set to investigate the challenges faced by preschool teachers in rural areas of Zambia, as well as the extent to which the government has provided support to ensure that there is quality delivery of early childhood education in rural areas.

There are numerous challenges faced by early childhood education teachers in rural areas of Western Province in Zambia. These problems have proved to be a menace towards the provision of early childhood education in various areas. However, not much has been established in terms of the extent of government's support in eradicating the challenges faced by early childhood teachers in rural areas.

\section{Literature review}

Early childhood is a crucial time period for the development of children's mental functions. This development, including the emergence of language, motor skills, psychosocial, cognitive, and learning abilities, is now known to be greatly influenced by exogenous factors, including the educational environment to which a child is exposed during the first 6 to 8 years of life (Bowman, Donovan and Burns, 2001).As regards benefits of early childhood education in Zambia, children that are exposed to early childhood education perform fairly well and better than those who had no opportunity for the preschool learning. In terms of inclusiveness of schools for early childhood education in Zambia, Despite government of the Republic of Zambia's effort and implementation of early childhood education, the provision of learning and teaching materials were not visible or catered for in any of the developments, very little if anything was happening to ensure that enough learning, teaching and infrastructure benefits the young children and teachers. The Public Health (Drainage and Latrine) Regulations makes it mandatory for any owner or occupier of schools to provide proper and sufficient latrine accommodation for girls and boys. (GRZ, 2009). This inability to support such provisions can 
be seen from several factors such as; absenteeism of children from school, lack of motivation on teachers, poor performance by children.

Children's sense of independence is supported when they can confidently and competently use equipment and when space and materials are adequate so that they can see what is available and make autonomous choices. This is in line with what Shepard and Eaton, (1997) states that children are more productively in activities when the purpose of classroom space is clearly defined and when materials are developmentally appropriate.

The early childhood environment should support the development of children as such this eases the teacher's burden. The early childhood environment must be spacious, with a lot of play materials for both indoor and outdoor activities. When there are enough learning and teaching materials, the school becomes relaxing, stimulating, exciting, thought provoking and challenging for the learners. Dodge (2004), asserts that a conducive environment enhances both fine and gross motor development through a range of appropriately challenging equipment and materials. This therefore, means that the teacher will not struggle to make children develop physically. The materials and equipment will provide the platform for learning. The teacher's role will be to facilitate and give guidance to ensure that children are safe.

'Free Education Policy' that was passed on by his excellence late former president Micheal Chilufya Sata (2012) who allowed enrolment of children without paying fees of any kind and attending school without uniforms can be seen as the government's effort to eradicate difficulties in accessing early childhood services.

The MoE states in its Strategic Plan 2003-2007 that Early Childhood Care and Education is an integral part of basic education, especially in the rural areas. The ability of many early childhood programs to provide high-quality services is in jeopardy because they lack sufficient resources to fully cover the costs of quality (NAETC, 1995). Lack of play materials and space for children leaves teachers more stressed because their learners seem not to enjoy learning and develop appropriately. Bredekamp \& Copple, (2010) alludes to play as an important vehicle for children's social and cognitive development, as well as a reflection of their development. Foundational skills impact the child's success in communication and language development, peer relationships, social adjustment, school success, and quality of life as an adult. When they are denied access to play material and adequate space, their interest and development seem to crumble. Teachers who handle these early childhood classes feel frustrated because their efforts are not seen such as holistic development due to limited space and lack of appropriate teaching and learning materials. (Heckman (2011).

Most early childhood environments in western province were generally not spacious enough, with no play materials for both indoor and outdoor activities. Very few schools had play parks and sizeable classrooms. Enough learning and teaching materials, makes the school to become relaxing, stimulating, exciting, thought provoking and challenging for the learners. The absence of all these facilities poses greater challenges to the teachers. (Prinsloo, 2005).

\section{ECE teachers' challenges}

\section{(a) Lack of infrastructure in ECE centers}

ECE teachers face common challenges in almost all areas. Most schools lack basic resources such as stationery, work cards and games posing a further challenge to the teachers and impacts negatively on the learners. In most cases, preschool teachers have to be creative in order to come up with these learning materials. A conducive environment also enhances children's self-esteem when it is designed with their needs and development in mind. The physical environment has a strong impact on both young children's learning and development. Environments that are well-designed will allow children to explore, give them a sense of control and will allow the children to engage in focused, self-directed play, and the social interaction which are meant to develop various skills, positive attributes and values. This is in line with Froebel (1985) who stated that play has a positive impact on students in their development; therefore, it should be a large part of the curriculum in schools. Pre-school teachers in the rural areas could be affected by lack of infrastructure. Infrastructure refers to the basic systems and services that are needed in order to support an economy, for example, transport and communication systems and electricity and water supplies: Early childhood education is very important and hence requires support 
from all stake holders. Education infrastructure includes suitable spaces to learn. This is one of the most basic elements necessary to ensure access to education. School classrooms are the most common place in which structured learning takes place with groups of children. (MOE, 1996).

While learning also takes place in a variety of different types of spaces - tents, temporary shelters, plastic sheeting, shade of trees, places of worship, people's homes, and so on-families and communities expected formal education to take place in classrooms that were designed for safety and comfort. Indeed, infrastructure plays a big role in the provision of early childhood education. When centers have poor infrastructure, children's movements are restricted both inside and outside the classroom, hence reducing active participation from young children. (Biber, 2006).

\section{(b) Lack of play parks}

Apart from learning materials, most preschools in the rural areas need to be furnished with play parks. Children need to be accorded chance to play outside. When children are able to select what they learn, they will be more engaged and able to attain the information. "Play allows young children to select their learning, especially if it facilitates their attainment of a broad range of developmental goals; therefore, it must be a vital component in the early childhood education curriculum" (Saracho, 2012).

Table showing the different resources obtained in rural and urban areas

\begin{tabular}{|l|l|l|}
\hline Items & Rural ECE centre & $\begin{array}{l}\text { Urban ECE } \\
\text { centre }\end{array}$ \\
\hline Swings & Not available & Available \\
\hline Desks & Only a few available & Available \\
\hline ECE classrooms & $\begin{array}{l}\text { Rooms without doors or } \\
\text { glass panes }\end{array}$ & Normal classrooms \\
\hline Toys & Not available & Available \\
\hline Mattresses/beds & Not available & Available \\
\hline Play parks & Not available & Available \\
\hline Outdoor equipment & Few and in bad shape & Available \\
\hline Flushables & Pit latrines & Available \\
\hline
\end{tabular}

Teaching younger children at preschool can take more work than it would on the primary level. Their motivation and desire to learn will largely depend on the availability of fascinating materials, which will require the teacher to be creative. The preschool teacher will be burdened with helping the preschooler in the foundation necessary for future academic success. Play stimulates children's physical, socio-emotional and cognitive development. Teachers who are not ECE trained may have difficulties on how to blend local knowledge such as popular folklore into children's activities and may not be well equipped to create a welcoming environment that stimulated creativity. They may also lack the skills to establish good communication with the children's parents. For children aged zero to six, learning should be a fun process, and educators must have the skills to guide the process. This is in line with (Ginsburg, 2013) who stated that play is important to healthy brain development. And so, applying these can help distinguish play from work, routines, rituals, and play-related behaviors like exploration and imitation.

\section{(c) Lack of assessment tools}

Another challenge was that of not having the right assessment tools for the preschool children. Assessment is the systematic process of gathering relevant information so that legal and instructional decisions are arrived at (Sternberg, 1998). Child assessment is an attempt to find out what a child can do and how he/she does it, and also to realize the effectiveness of the teacher. After all, teaching and learning are reciprocal processes that influence each other and only through assessment can it be determined how well the teacher was teaching and how well the student or child was learning (Kellough \& Kellough, 1999). Information on assessment helps in planning a curriculum to meet the child's individual needs. Assessment occurs within the context of everyday experiences; beginning with the information and observations shared by family members. As the child moves from home to the preschool, assessment continues as teachers and other staff members observe and record behaviours 
throughout the day. These systematically collected observations inform instructional practices about how to support children's strengths and abilities and provide the foundation for meaningful parentteacher conferences about a child's progress. An assessment tool with a clear protocol that measures children's progress in all learning domains is critical. Assessment tools such as Child Development Assessment Tool for Zambia (CDATZ) should be used.

Poverty is another issue that affects the delivery of early childhood education. When truancy among children is high, teachers may be required to repeat certain topics to make the children catch up, which would be an extra job for teachers. This is in line with what Joubert (2010) alluded to a situation of poverty in South Africa, despite government efforts to relieve adversity, poverty in rural areas was still rife and poor education still failed to lift people out of it. There is nothing frustrating to a teacher than poor performance of his learners. The impact of poverty and illiteracy on the development of rural children must be acknowledged and addressed. Many rural children lack basic resources, and without them, effective learning and the development of effective writing skills will continue to be hampered. The challenge of poverty breeds a number of factors that are detrimental in the delivery of education. (Nussbaum, 2010).

\section{Methodology}

Data was collected from four (4) schools with ECE centers in Mongu district, by the use of oral interviews and questionnaires. The researcher personally visited the selected schools to collect data. A sample size of four participants namely; the head teacher, one senior teacher, one ECE teacher and one parent from each school under research were interviewed. Each respondent was interviewed separately and anonymity was upheld during the process.

\section{Analysis of the research}

The challenges faced by ECE teachers in rural areas may not be the same in township schools. Though the number of schools visited may not represent the whole western province, the responses obtained gave a clear picture of what was prevailing on the ground. Some Faith Based Organizations (Catholics) supplemented government efforts but only schools in the towns benefited from the support because some places in the rural areas were impassable, and even when support was given, it was like a drop in the ocean because the schools were many. This is in line with (Heckman 2000) who echoes the need to support early childhood education in rural areas where he stated that "We cannot afford to postpone investing in children until they become adults, nor can we wait until they reach school agea time when it may be too late to intervene." Learning is a dynamic process and is most effective when it begins at a young age and continues through to adulthood.

The research revealed that the teaching methods in the curriculum were not applicable to some of the rural ECE centers due to limited space and unavailability of man power. Standing (1957) explained that the environment should exhibit the following characteristics, free from harmful objects, spacious with appropriate playing instruments. Where these facilities are not available, there can never be quality education.

The curriculum therefore should be flexible to the environment. If we were to attain the sustainable goals, the issue of quality education must be made available to all schools regardless of locations and teachers, learning and teaching materials must be distributed equally.

\section{Research findings}

Lack of proper infrastructure is a challenge emanating from this research which has a telling effect on the provision of early childhood education in Zambian schools. Most schools visited were grass thatched and made of mud and pole. This unpleasant situation which was equally lamented by the former Minister of Education Dr. John Phiri that out of 518 grass thatched schools in the country, 149 are in Western Province. (MOE 2013). This research has found that the situation has not changed, meaning that there has been less government effort in eradicating this challenge. In addition, the ECE centers are faced with lack of running water for proper sanitation as characterized by the absence of flushable toilets and the influx of ventilated improved pit latrines (VIPs). It is clear that the nature of toilets available in the ECE centers in Mongu district are not safe for young children at preschool. No 
DOI: $10.21522 /$ TIJAR.2014.06.01.Art008

ISSN: $2520-3088$

effort is seen to have been made by government in order to curb this unsafe situation for learners at preschool level.

Equally, the need for play facilities which are conspicuously absent in ECE centers cannot be overemphasized. This clearly demotivates the learners and renders the teacher's work very difficult has he or she has to find alternative means of motivating the learners, a thing which is difficult to do in rural areas where there are generally no recreation facilities.

Teaching methods advanced by the curriculum leave much to be desired as they tend to be inapplicable in most rural schools. Very little has been done by government to resolve this challenge as the recent curriculum reform was only for the higher grades.

Lack of proper infrastructure in ECE centers in Zambian schools has also proved to be a hindrance to teacher retention in rural areas as most of them could not cope with rural life, resulting in poor teacher-pupil ration in schools such as Sefula, Malabo, Mawawa and Mulambwa. Unfortunately, government has not deployed enough teachers to these rural schools, while urban schools have been flooded with teachers.

The lack of ECE teachers also entails that the teachers have to handle more than one class, thereby causing a serious gap in the efficient delivery of ECE services as it calls for more time to plan and execute. This extra burden seems not to be lessened as there were lesser efforts made to motivate such teachers as could be seen in their lack of extra duty allowances.

The research revealed that the distance covered by children was so high that it resulted in high levels of absenteeism among the pupils. This increased the teachers' pressure as they have to repeatedly go back to what has been covered in order to enable those who missed to catch up with others. The long distance covered equally has an effect on the children's nutrition. Unfortunately, there are no deliberate feeding programs put in place for preschool children in the ECE centers. This aggravates the teacher's challenge as they have to find alternative means of motivating these usually hungry children to learn. This is coupled by natural causes affecting the school such as annual flooding as is the case with Malabo Primary school. Poverty and general underdevelopment of the rural areas pose a danger to the educational welfare of preschool children.

The preschool teachers evidently lacked teaching and learning materials. This challenge has a very significant bearing on the quality delivery of ECE services in schools. In this way, the value of teaching and learning materials is compromised to a very large extent in ECE centers. Needless to say, is the fact that the efforts to improve the supply of these materials have seemingly been left in the hands of the private sector. Lack of a sufficient number of textbooks was a recurring problem in most rural, if not all, primary and basic schools in Western Zambia. Due to this lack of materials, teachers struggle with the problem of engaging all students in the lesson. The lack of materials was not solely an issue for learners, but an insufficient number of teacher manuals was a problematic for teachers, as well. Preparation for classes has become a major task for most teachers in the most rural areas where means of gathering information and conducting research are difficult. This is aggravated by lack of libraries and internet access. One Deputy Head teacher noted that the challenge for teachers to provide quality instruction resulted from lack of teacher manuals.

Given the severity of over-crowding in Zambian schools, it seemed unreasonable that international aid agencies highlighted the benefits of ECE, since they often utilized studies conducted in countries with pupil/teacher ratios between 4:1 and 10:1 as their basis (Penn, 2004) which were not attainable in rural areas related to the problems of over-enrollment and large class size was the number of teachers who were employed by the government.

Early Childhood Education teachers had many challenges in rural areas ranging from poor infrastructure, lack of teaching and learning materials, transport, distances, lack of motivation of ECE teachers and poverty levels that hinders adequate participation by both parents and children. For many teachers, the poor state of their working environment reinforces their belief that society undervalues the work they do. Staffrooms were often overcrowded; the furniture were old and frequently dysfunctional and storage facilities inadequate. Cramped staffroom conditions were often cited as a reason for not accepting teachers. In some schools, early childhood children had no permanent classroom, instead they are made to learn from offices or they were made to shift from one classroom to another. This in itself demoralized the early childhood teacher. 
Over enrolment in government pre-schools was a big challenge because most parents could not afford high fees charged by private preschools and hence the high numbers in government schools. For instance, enrolment at Mulambwa Primary school in a reception class was 58, while at Unique international (private) in a reception class was 26. Larger numbers of children per teacher revealed less verbal interaction among the teachers and the children. Teachers who have lower ratios in their classrooms are more sensitive and responsive to the children than teachers who had more children in their classroom (Howes, 2009). The size of children in a classroom is an important factor in providing quality care because children will be given individualized attention unlike when a teacher is responsible for a large number of children whereby the teacher will be unable to provide such attention but instead the teacher will be more concerned with controlling and managing the group. In this vain, NAEYC suggests a ratio of 10 to 1 for four and five-year-olds for Developmentally Appropriate Practices (Bredekamp \& Copple, 2010). However, most rural preschool teachers had a challenge of over enrolment in their classroom because the preschool may be the only nearer center in a particular area. When a teacher was in charge of a smaller group, they tend to interact more and become cooperative, innovative and demonstrate greater social competence (Clarke-Stewart, 2008).

\section{Conclusion}

Early childhood education teachers face various challenges in their quest to deliver quality education to young learners in Zambia. These challenges are enhanced further by poverty and underdevelopment in rural areas which serve as a litmus test on the effectiveness of the government efforts to alleviate these numerous problems faced by early childhood education teachers in their daily tasks of delivering education to the young children. The lack of adequate government support to eradicate these challenges has repeatedly been bemoaned by the researcher and other concerned stakeholders. It is in view of this that it is recommended that government scales up its efforts to improve the provision of ECE by partnering with other stakeholders from various sectors of society. This would culminate into an effective and meaningful improvement in the welfare of preschool teachers in the execution of their duties.

\section{References}

[1]. Barnett W S. (Fall/Winter). Long-term effects of early childhood programs on cognitive and school outcomes. The future of children: Long-term outcomes of early childhood programs, 1995; 5(3):25-50.

[2]. Biber, B. (2006). Early education and psychological development. New Haven, CT: Yale University Press. [3]. Bowman, B., M Donovan and M. Burns, eds. 2001. Eager to Learn: Educating Our Preschoolers, Committee on Early Childhood Pedagogy, Commission on Behavioral and Social Sciences and Education, National Research Council, National Academy Press, Washington, DC.

[4]. Bredekamp, S., and Copple, C. E. (Eds.) (2010) developmentally appropriate practice in early childhood programs serving children from birth through age 8 (Rev.ed.). Washington, DC: National Association or the Education of Young Children.

[5]. Bronfenbrenner, U. (2009). The ecology of human development. Cambridge. MA: Havard University Press. [6]. Clarke-Stewart, (2008). Predicting child development from child care forms and features. Chicago Study. In D.A. Phillips (Ed.), Quality in child care: What does research tell us? (pp. 21-41). Washington, DC: National Association for the Education of Young Children.

[7]. Cohen L, Manion L \& Morrison K. 2008. Research methods in education. 6th Edition. London: Routledge Cohen L, Manion L \& Morrison K. 2008. Research methods in education. 6th Edition. London: Routledge.

[8]. Cuffaro, H., K., Nager, N., Shapiro, E. K. (2000). The Developmental-Interaction Approach at Bank Street College of Education. In J. L. Roopnairine \& J. E. Johnson (Eds.) Approaches to early childhood education ( $3^{\text {rd }}$ ed.) Upper Saddle River, NJ: Merrill.

[9]. Forget-Dubois, N., J. Lemelin, M. Boivin, G. Dionne, J. Seguin, F. Vitaro, and R. Tremblay. (2007). "Predicting Early School Achievement With the EDI: A Longitudinal Population-Based Study" Early Education and Development. 18:3, 405-426.

[10]. Froebel, Friedrich. 1895 [1985]. Friedrich Froebel's Pedagogics of the Kindergarten: Or, His Ideas Concerning the Play and Playthings of the Child. New York: D. Appleton. 
DOI: 10.21522/TIJAR.2014.06.01.Art008

ISSN: $2520-3088$

[11]. Government of the Republic of Zambia Sixth National Development Plan 2011-15. Lusaka: Cabinet Office, 2011.

[12]. Heckman, J. (2011). The economics of inequality: the value of early childhood education. Am Educ, 35(1), $31-35$.

[13]. Hong, X, \& Luo, L. (2012). Analysis of differences in preschool education development in urban and rural China from the perspective of education equity. Educ Stud, 8(5), 73-81. In Chinese.

[14]. Howes, C. (2009). Care giver behavior in centre and family day care. Journal of Applied Developmental Psychology: 4, 99-107.

[15]. Howes, C. (2010). Children's experience in centre-based child care as a function of a teacher background and adult-child ratio. Merrill-Palmer Quarterly: 43, 404-425.

[16]. Hu, BY, \& Roberts, SK. (2013). A qualitative study of the current transformation to rural village early childhood in China: Retrospect and prospect. Int J Educ Dev, 34, 316-324.

[17]. Kamerman, S. B. (2006). A global history of early childhood education and care. Paper commissioned for the EFA Global Monitoring Report 2007, Strong foundations: Early childhood care and education. UNESCO: Paris.

[18]. Ministry of Education (1996), Educating Our Future: National policy on education, Lusaka: Zambia Educational Publishing House.

[19]. Ministry of Education. (2006). Fifth national development plan 2006-2010. Zambia: Poverty reduction strategy paper. Retrieved November 13, 2008

[20]. Nussbaum, C. M, 2010, Not for profit: Why democracy needs the humanities,

[21]. Princeton: Princeton University Press.

[22]. Penn, H. (2004). Childcare and early childhood development programmes and policies: Their relationship to eradicating child poverty. Childhood Poverty Research and Policy Centre, CHIP Report No. 8. Retrieved November 14, 2008.

[23]. Prinsloo, E. (2005). Socio-economic barriers to learning in contempory society. In: E Landsberg (ed). Addressing barriers to learning: A South African perspective. Pretoria: Van Schaik. 27-41.

[24]. Saracho, O. N. (2012). An integrated play-based curriculum for young children.

[25]. Sheperd, W., \& Eaton, J. (1997). Creating environments that intrigue and delight children and adults. Child Care Information Exchange, 117, 42-47.

[26]. Yao, B. and Y. Xie. 2004. Thought on Current Situation of Kindergarten Teachers in Rural Areas, Kid Education, (7-8). 